Int. J. Dev. Biol. 61: 293-302 (2017)

doi: $10.1387 / \mathrm{ijdb} .160300 \mathrm{df}$

\title{
FoxD1 protein interacts with Wnt and BMP signaling to differentially pattern mesoderm and neural tissue
}

\author{
HANNA POLEVOY\#, ANASTASIA MALYAROVA*, YURI FONAR, SARA ELIAS and DALE FRANK* \\ Department of Biochemistry, The Rappaport Family Institute for Research in the Medical Sciences, \\ Faculty of Medicine, Technion - Israel Institute of Technology, Haifa, Israel
}

\begin{abstract}
The foxd1 gene (previously known as Brain Factor 2/BF2) is expressed during early Xenopus laevis development. At gastrula stages, foxd1 is expressed in dorsal mesoderm regions fated for muscle and notochord, while at neurula stages, foxd 1 is expressed in the forebrain region. Previous studies in the neural plate showed that FoxD1 protein acts as transcriptional repressor downstream of BMP antagonism, neuralizing the embryo to control anterior neural cell fates. FoxD1 mesoderm function was not rigorously analyzed, but ectopic FoxD1 levels increased muscle marker expression in embryos. Using a FoxD1-specific antisense morpholino oligonucleotide, we knocked down endogenous FoxD1 protein activity in developing Xenopus embryos. In this present study, we show that FoxD1 is crucial for dorsal mesoderm formation. Analogous to neural tissue, FoxD1 acts downstream of BMP antagonism to induce dorsal mesoderm cell fates, such as muscle and notochord. FoxD1 is sensitive to its local signaling environment, having differential transcription factor activity in the presence or absence of Wnt or BMP signaling. FoxD1 induces posterior neural tissue in the presence of Wnt or BMP activities, but its activity is restricted to "normal" anterior neural tissue induction when BMP and Wnt activities are repressed. In dorsal mesoderm, FoxD1 interacts with Wnt signaling and BMP antagonism to induce muscle and notochord, while simultaneously repressing more anterior and ventral mesoderm cell fates. FoxD1 protein has multiple activities that are masked or released in the different germ layers as a function of the local signaling environment.
\end{abstract}

KEY WORDS: Forkhead gene, Xenopus, neural patterning, mesoderm patterning, canonical Wnt signaling

\section{Introduction}

Pattern formation during early embryo development is dependent on an intricate relationship between signaling pathways and transcription factors (Gerhart, 2015). Signaling pathways can nonautonomously induce expression of transcription factors in adjacent cells, which will then autonomously control that cell's specific fate. In turn, transcription factors can induce expression of downstream signaling ligands that act non-autonomously on neighboring cells to alter their fate from that of their adjacent inducing neighbor. During early development, apparent redundant expression of signaling pathways and transcription factors is widespread throughout and within the developing germ layers, yet despite this apparent overlap in expression or activities, cells manage to sort this information out, and differentiate correctly. Understanding how similar signals lead to different cell fate outcomes has been enigmatic to elucidate dur- ing early development. We have addressed this question with the Forkhead Winged-helix transcription factor protein, FoxD1 (Mariani and Harland, 1998; Gómez-Skarmeta et al., 1999).

The foxd 1 gene is expressed during two phases of early Xenopus laevis development. In gastrula stage embryos, it is expressed in the dorsal and dorsal-lateral marginal zone regions fated for muscle and notochord, while in neurula stage embryos, foxd 1 is expressed in the forebrain region (Mariani and Harland, 1998; Gómez-Skarmeta et al., 1999). Little is known about FoxD1 mesoderm function, but its ectopic embryonic expression increased muscle marker levels (Gómez-Skarmeta et al., 1999). More extensive studies examined

Abbreviations used in this paper: AC, animal cap; AP, anteroposterior; BMP, bone morphogenetic protein; DLMZ, dorsal-lateral marginal zone; DMZ, dorsal marginal zone; DV, dorsoventral; MO, morpholino oligonucleotide; VMZ, ventral marginal zone.

\footnotetext{
*Address correspondence to: Dale Frank. Department of Biochemistry, The Rappaport Family Institute for Research in the Medical Sciences, Faculty of Medicine, Technion - Israel Institute ofTechnology, Haifa 31096, Israel. Tel: 972-48-295286. Fax: 972-48-553299. E-mail: dale@ @x.technion.ac.il (iD) http://orcid.org/0000-0002-1857-6820
}

\#Note: The indicated authors contributed equally to this paper.

Accepted: 5 October, 2016.

ISSN: Online 1696-3547, Print 0214-6282 
the role for FoxD1 at neurula stages. Utilizing ectopic expression of FoxD1 hypermorph and antimorph proteins, FoxD1 was shown to act as a transcriptional repressor that has strong neuralizing activity (Mariani and Harland, 1998). In Xenopus animal cap (AC) explants, foxd1 expression is activated by BMP antagonists; subsequently, FoxD1 activates downstream expression of panneural and anterior markers by repressing bmp4 gene expression (Mariani and Harland, 1998). Ectopic FoxD1 neuralizes embryos, and expands expression of panneural markers; while more differentiated subtypes of cells, such as primary neurons and neural crest are reduced (Mariani and Harland, 1998). Ectopic FoxD1-VP16 antimorph protein levels inhibit neural marker expression in embryos (Mariani and Harland, 1998). In AC explants, ectopic FoxD1 levels induced panneural and forebrain marker expression, which might be expected for a neural inducing factor acting downstream to BMP antagonism. Somewhat counterintuitively, ectopic FoxD1 also induced expression of more posterior hindbrain and spinal cord neural markers (Wallingford and Harland, 2001; Borchers et al., 2008; Fonar et al., 2011). These ACs also underwent neural convergent extension morphogenesis that is associated with hindbrain and spinal cord fates (Wallingford and Harland, 2001; Borchers et al., 2008; Fonar et al., 2011). It is somewhat puzzling that a forebrain-specific protein like FoxD1 can efficiently induce posterior neural cell fates in these explants. However, our previous studies partially explain this enigma. In AC explants neuralized by FoxD1, wnt3a gene expression is induced; this Wnt-activity is required for neural caudalization by FoxD1 (Fonar et al., 2011).

To further advance our understanding of FoxD1 function in neural and mesoderm patterning, we examined the interaction of FoxD1 protein with the canonical Wnt and BMP pathways. These pathways have crucial roles in both mesoderm and neural patterning (Kimelman, 2006; Elkouby and Frank, 2010). We found that FoxD1 acts as a strong inducer of anterior neural fates in embryos and explants depleted of canonical Wnt signaling, versus controls. This is typical of the forebrain region, where Wnt activity is low, and the foxd1 gene is normally expressed. FoxD1 cannot induce posterior neural markers in the absence of Wnt signaling. In the mesoderm, we show that FoxD1 protein is required for muscle and notochord fates, while concomitantly repressing ventral and anterior fates. BMP antagonism activates foxd 1 expression in dorsalized mesoderm explants. In dorsalized explants, FoxD1 protein acts downstream of BMP antagonism to induce dorsal mesoderm fates, similar to its role as a mediator of BMP antagonism in the neural plate. FoxD1 requires canonical Wnt activity to induce muscle in the dorsal lateral mesoderm, but not notochord in the more dorsal regions where Wnt signaling is normally inhibited and low. Thus, in both neural and mesoderm tissue, FoxD1 acts downstream to BMP antagonism to differentially pattern tissue fates via canonical Wnt signaling.

\section{Results}

\section{FoxD1 has enhanced anterior neural inducing activity in the absence of canonical Wnt-signaling}

To address FoxD1/Wnt interplay, we examined embryos (Fig. 1A) co-expressing ectopic FoxD1 and Dkk1 proteins. Ectopic FoxD1 expression alone gives the typical neuralized phenotype (Fig. 1B), whereas ectopic expression of Dkk1 gives a representative anteriorized phenotype with a shortened-truncated body axis hav- ing an enlarged head and cement gland (Fig. 1C). However upon co-expression of both proteins, the embryos lost all axial structure, having a highly anteriorized body plan, with a radial cement gland (Fig 1D). Thus, ectopic FoxD1 activity strongly enhanced neural anteriorization induced by Dkk1 protein.

Similar results were seen in AC explants. FoxD1 induces expression of wnt3a in ACs and this downstream Wnt activity seems to mediate FoxD1 activation of posterior neural markers in ACs (Fonar et al., 2011). ACs that express ectopic FoxD1 alone activate a representative group of neural markers expressed along the anteroposterior (AP), as well as panneural markers (Fig. 2A, lane 4). In ACs, ectopic FoxD1 and Dkk1 protein levels increased anterior xanf1, xag1 and otx2 marker expression (Fig. 2A, lane 4 versus 6), whereas expression of the more posterior krox20, hoxb9and $n$-tub markers is highly reduced (Fig. 2A, lane 4 versus 6). Expression of the panneural markers, nrp1 and ncam is unchanged (Fig. 2A, lane 4 versus 6), These results show that FoxD1 does not require Wnt signaling for general neural induction, just neural patterning. Dkk1 alone does not significantly modulate neural marker expression in ACs (Fig. 2A, lane 5).

In reciprocal experiments, Wnt3a was ectopically co-expressed with FoxD1 protein in ACs. Anterior marker expression (xanf1, xag1, otx2) induced by FoxD1 was repressed; posterior neural marker expression was enhanced (krox20, hoxb9); and panneural marker (ncam and nrp1) expression was unaltered (Fig. 2B, compare lane 4 versus 6). Under these experimental conditions, ectopic Wnt3a expression alone did not strongly activate expression of posterior neural markers, but only enhanced their expression in the presence of FoxD1 protein (Fig. 2B, compare lanes 4-6). Ectopic FoxD1 induces moderate elongation of ACs, typical of posterior neural convergent extension cell movements (Wallingford and Harland, 2001). In a typical representative experiment, FoxD1 induces moderate-strong elongations in about $15 \%$ of the explants, whereas FoxD1/Wnt3a co-expression enhances elongations about four fold to about $60 \%$ (not shown). In comparison, FoxD1/Dkk1
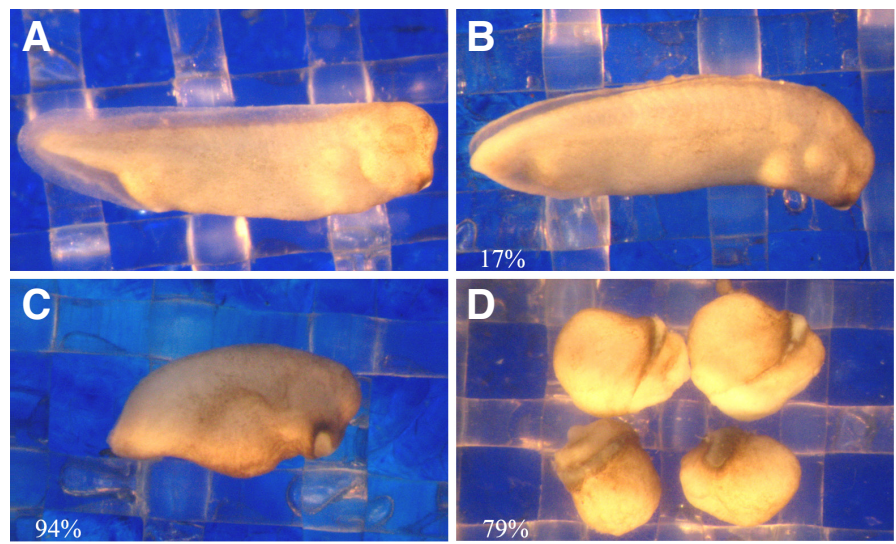

Fig. 1. FoxD1 protein is a more potent neural anteriorizer when canonical Wnt activity is inhibited. (A) Morphology of tail-bud stage 33-34 ( $n=27)$ embryos injected at the one-cell stage with foxd1 (10 pg) or dkk1 (30 pg) mRNAs. (B) Ectopic FoxD1 protein caused a bent-neuralized phenotype in some of the embryos ( $n=35,17 \%$ bent). (C) Ectopic Dkk1 protein reduced posterior neural regions and enlarged anterior structures in $94 \%$ of the embryos ( $n=33$ ). (D) Co-expression of Foxd1/Dkk1 proteins strongly eliminated posterior neural structures, inducing a highly anteriorized embryo body, forming radial heads/cement glands in $79 \%$ of the embryos $(n=28)$. 
co-expression reduces elongation (not shown). These results support the finding that FoxD1 protein caudalizes neural cell fates via Wnt signaling.

\section{FoxD1 caudalizing activity can be uncoupled from neural induction in animal cap explants}

Foxd1 and BMP4 proteins were co-expressed to determine if FoxD1 acts independently of neural induction to activate posterior neural marker expression. At early neurula stages, xanf1/otx2 (forebrain), gbx2 (hindbrain), n-tub (primary neuron) and ncam (panneural) gene expression was induced by FoxD1 inACs (Fig. 3A, lane 4). Hoxb9 and $c d x 1$ markers (spinal cord) were not detected at this stage (Fig. 3A, lane 4). Co-expression of BMP eliminated neural induction, as measured by ncam and xanf1 expression (Fig. 3A, lane 4 versus 6). BMP was permissive for $g b x 2$ and $n$-tub expression, while stimulating the more posterior hoxb9 and $c d x 1$ expression (Fig. 3A, lane 4 versus 6). BMP4 alone did not significantly induce posterior neural markers at these concentrations (Fig. 3A, lane 5). Similar results were also seen in late neurula stage $A C$ explants. FoxD1 induced expression of xanf1, otx2, xag1, hoxb9, cdx1, cdx4 and ncam (Fig. 3B, lane 4). Ectopic BMP enhanced FoxD1 induction of spinal cord specific $c d x 1, c d x 4$ and hoxb9 expression, while repressing xanf1, otx2, xag1 and ncam expression levels (Fig. 3B, lane 4 versus 6). BMP alone did not induce hoxb9, $c d x 1$ or $c d x 4$ expression (Fig. 3B, lane 5). These results show that FoxD1 has an intrinsic ability to induce expression of posterior neural markers when uncoupled from neural induction mediated by BMP antagonism, presumably by its ability to activate Wnt signaling via induction of wnt3a gene expression (Fonar et al., 2011). Neural uncoupled induction of posterior neural markers has been shown in naïve ACs for other proteins, like Wnt3a or the TALE-class homeobox protein Meis3, which activates posterior markers downstream to Wnt signaling in the absence of activating panneural marker expression (Dibner et al., 2001; Elkouby et al., 2010). In Xenopus, foxd1 gene expression
A

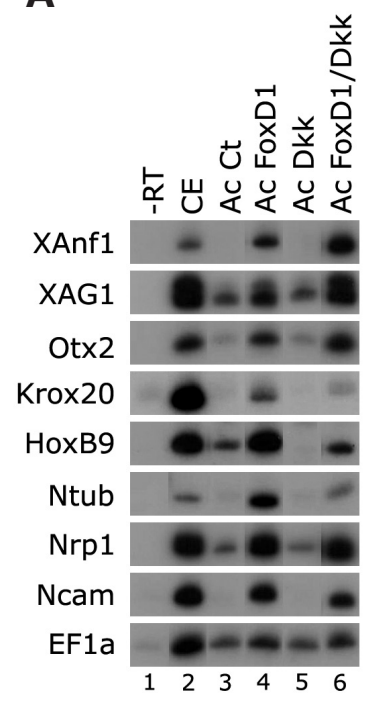

B

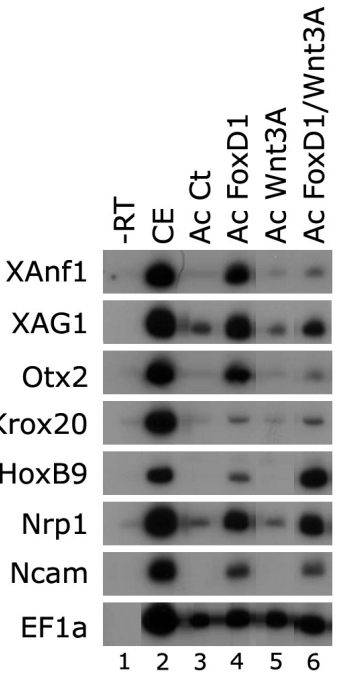

A

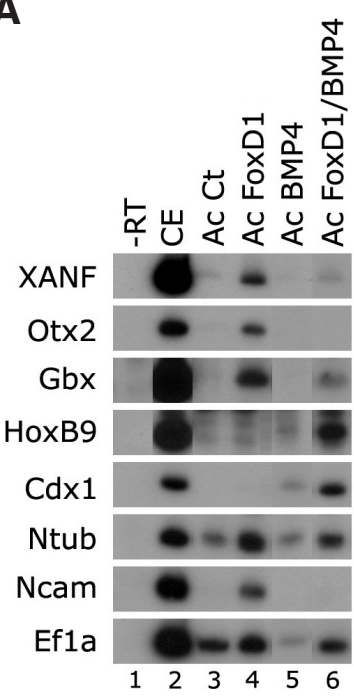

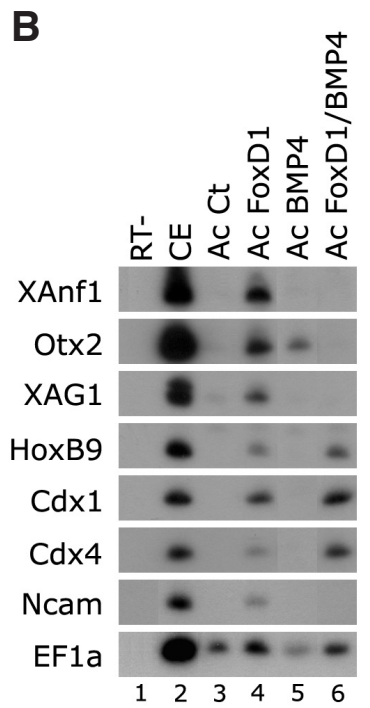

Fig. 2 (left). FoxD1 neural patterning activity is modified via canonical wnt signaling. (A) Embryos were injected animally at the one-cell stage with mRNAs encoding foxd1 (50 pg) or dkk1 (25 pg) proteins. AC explants were removed from control and injected embryos at blastula-stage and grown to neurula stage 17. Total RNA was isolated from five control embryos (lane 2) and eighteen ACs from each group (lanes 3-6). Various neural AP markers were examined by sqRT-PCR: anterior forebrain and cement gland (xanf1, xag1, otx2), posterior hindbrain, spinal cord and primary neuron markers (krox20, hoxb9, ntub) and panneural markers (nrp1, ncam). In the different samples, ef1 $\alpha$ serves as a control for quantitating RNA levels. -RT-PCR was performed on total RNA isolated from control embryos (lane 1). (B) Embryos were injected animally at the one-cell stage with mRNA encoding foxd1 (20 pg) protein or a CMV-driven plasmid vector (20 pg) driving wnt3a expression. ACs were removed from control and injected embryos at blastula-stage and grown to neurula stage 17. Total RNA was isolated from five control embryos (lane 2) and eighteen ACs from each group (lanes 3-6). Various neural AP markers were examined by sqRT-PCR: anterior forebrain and cement gland (xanf1, xag1, otx2), posterior hindbrain and spinal cord markers (krox20, hoxb9) and panneural markers (nrp1, ncam). In the different samples, ef1 $\alpha$ serves as a control for quantitating RNA levels. -RT-PCR was performed on total RNA isolated from control embryos (lane 1).

Fig. 3 (right). FoxD1 neural caudalizing activity is uncoupled from its neural-anteriorizing activity. (A) Embryos were injected animally at the one-cell stage with mRNAs encoding foxd1 $(25 \mathrm{pg})$ or BMP4 $(250 \mathrm{pg})$ proteins. AC explants were removed from control and injected embryos at blastula-stage and grown to late gastrula/early neurula stage. Total RNA was isolated from five control embryos (lane 2) and eighteen ACs from each group (lanes 3-6). Various neural AP markers were examined by sqRT-PCR: anterior forebrain markers (xanf1, otx2,), posterior hindbrain, spinal cord, and primary neuron markers (gbx2, hoxb9, cdx1, ntub) and the panneural marker (ncam). In the different samples, ef1 $\alpha$ serves as a control for quantitating RNA levels. -RT-PCR was performed on total RNA isolated from control embryos (lane 1). (B) Embryos were injected animally at the one-cell stage with mRNAs encoding foxd1 (25 pg) or BMP4 (250 pg) proteins. AC explants were removed from control and injected embryos at blastula-stage and grown to mid-late neurula stage. Total RNA was isolated from five control embryos (lane 2) and eighteen ACs from each group (lanes 3-6). Various neural AP markers were examined by sqRT-PCR: anterior forebrain and cement gland markers (xanf1, otx2, xag1), posterior spinal cord markers (hoxb9, cdx1, $\mathrm{cdx} 4$ ) and the panneural marker (ncam). In the different samples, ef1 $\alpha$ serves as a control for quantitating RNA levels. -RT-PCR was performed on total RNA isolated from control embryos (lane 1). 
is restricted to the forebrain region. This region is characterized by a strong inhibition of canonical Wnt and BMP signaling (Niehrs et al., 2001). Thus under normal physiological conditions, FoxD1 is primed to induce anterior neural tissue. In AC explants permissive for BMP and canonical Wnt activities, intrinsic FoxD1 neural caudalizing is unmasked, which is not in the correct cellular context of normal FoxD1 protein function and activity in vivo. These results
A
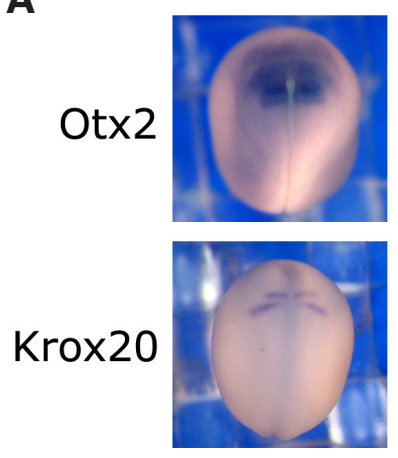

HoxB9

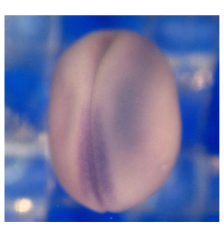

CE
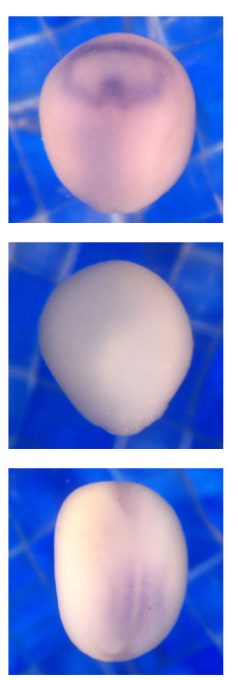

FoxD1 MO 20ng
B

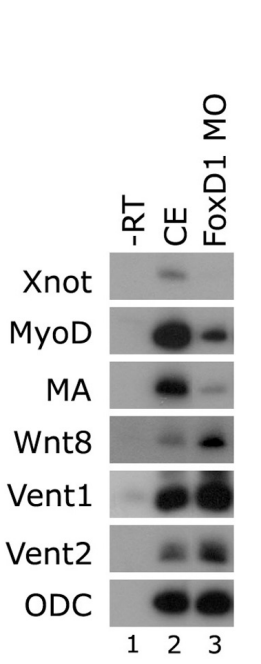

E

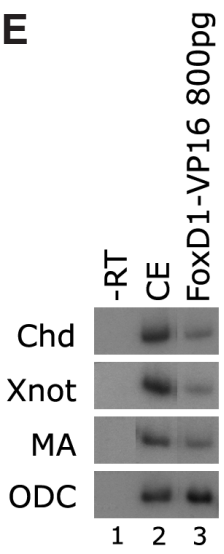

$F$ thus show that FoxD1 protein neural patterning activities are a result of the local signaling environment in the embryo.

\section{FoxD1 protein knockdown reduces neural and dorsal mesoderm cell fates}

To further investigate function in Xenopus, FoxD1 protein was knocked down by the FoxD1-MO. Previous loss-of-function studies

C

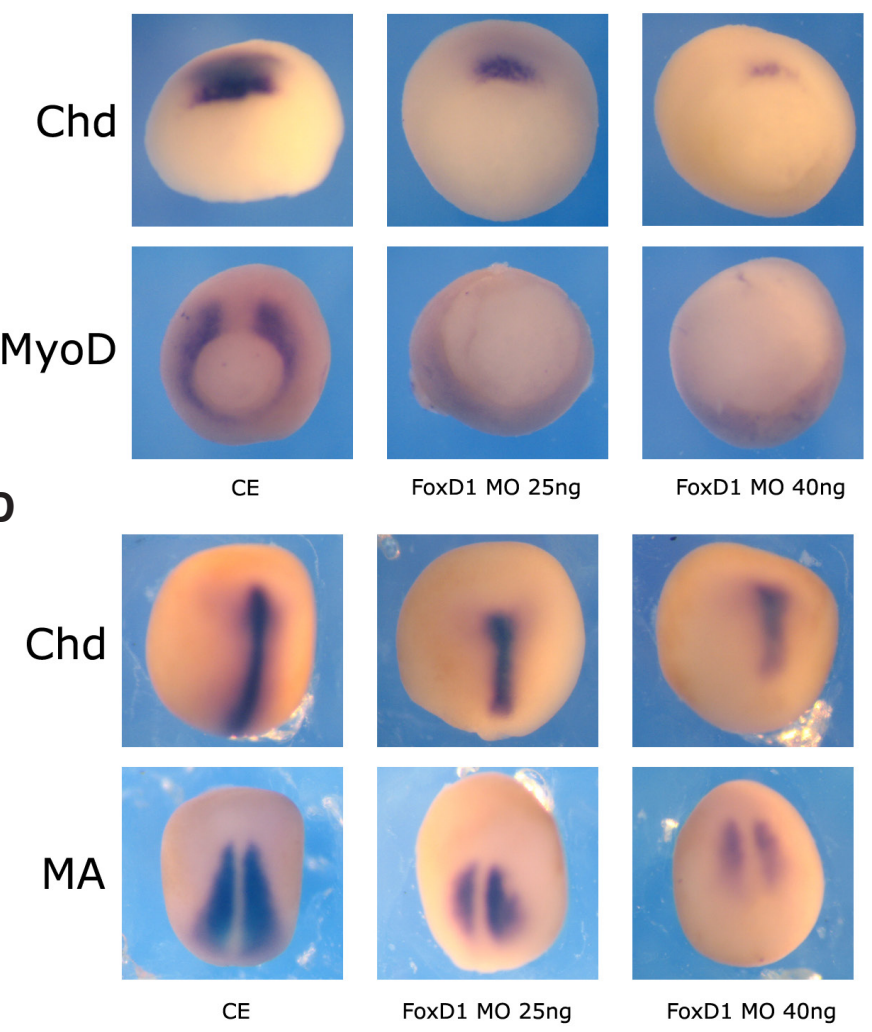

Fig. 4. FoxD1 knockdown by the FoxD1-MO eliminates both neural and dorsal mesoderm cell fates. (A) One-cell stage embryos (left panel) were injected animally with the FoxD1-MO (20 ng, right panel). Using in situ hybridization, cell fates along the neural AP axis were examined at neurula stage 17. Three AP markers were examined; otx2 for the mid-forebrain region, krox20 for the hindbrain, and hoxb9 for the spinal cord. In FoxD1

morphants, otx2 expression was reduced in 100\% of the embryos ( $n=19)$; krox20 expression was reduced in either one or both rhombomeres in $69 \%$ of the embryos ( $n=13)$, and hoxb9 expression was inhibited in $77 \%$ of the embryos ( $n=13)$. (B) One-cell stage embryos were injected marginally with the FoxD1-MO (25 ng). Total RNA was isolated from pools of five control (lane 2) or FoxD1 morphant embryos (lane 3) at late neurula stages. sqRT-PCR was carried out to mesoderm markers expressed along the dorso-ventral axis: xnot (dorsal notochord), myod and muscle actin MA (dorsal-lateral muscle) and vent1, vent2 and wnt8 (ventral). odc serves as a control for quantitating RNA levels. (C) One-cell stage embryos were injected marginally with two concentrations of the FoxD1-MO (25 and $40 \mathrm{ng}$ ). In situ hybridization was performed to early gastrula embryos, stage 11-11.5. Expression of the dorsal chd marker (upper panels) was reduced at both FoxD1-MO concentrations in 78\% of the embryos ( $n=23$ ). Expression of the dorsal-lateral myod marker was also reduced in 93\% of the FoxD1 morphant embryos ( $n=15)$. (D) One-cell stage embryos were injected marginally with the two concentrations of the FoxD1-MO (25 and $40 \mathrm{ng}$ ). In situ hybridization was performed to neurula embryos, stage 14-15. Expression of the notochord chd marker (upper panels) was reduced at both FoxD1-MO concentrations in 100\% of the embryos ( $n=25)$. Expression of the muscle MA marker was also reduced in 68\% of the morphant embryos ( $n=19)$. Two other notochord and muscle markers, xnot and myod were also inhibited to similar levels in the same experiment (not shown). (E) One-cell stage embryos were injected marginally with the mRNA (800 pg) encoding the foxd1-vp16 antimorph protein. Total RNA was isolated from pools of five control (lane 2) or FoxD1-VP16 antimorph protein expressing (lane 3) embryos at late neurula stage 16. sqRT-PCR was carried out to the mesodermal markers: xnot, chd, and MA. (F) One-cell stage embryos (lane 2) were injected either marginally (left panel) or animally (right panel) with the FoxD1-MO (20 ng, lane 3), mRNA encoding the foxd1 (25pg) protein (lane 5) or both (lane 4). Total RNA was isolated from pools of seven embryos in each group. In the left panel, sqRT-PCR was performed on RNA isolated from gastrula stage 11 embryos to address the rescue of myod expression by ectopic FoxD1 protein over expression (compare lanes 3-5). Xhis serves as a control for quantitating RNA levels. In the right panel, sqRT-PCR was performed on RNA isolated from neurula stage 16 embryos to address the rescue of ncam expression by FoxD1 (compare lanes 3-5). 
used ectopic expression of the FoxD1-VP16 antimorph protein (Mariani and Harland, 1998). All AP neural fates were perturbed in FoxD1 morphant embryos. Using both sqRT-PCR (not shown) and in situ hybridization, we detected large reductions in expression of the anterior otx 2 (forebrain) marker, as well a reduction of more posterior krox20 (hindbrain) and hoxb9 (spinal cord) markers (Fig. 4A, left versus right panel), Expression of the panneural ncam marker was also reduced (not shown). These results recapitulated the FoxD1 antimorph protein (Mariani and Harland, 1998). The reduction of posterior neural markers like hoxb9 and krox20 is presumably due to the overall reduction in general neural cell fates, similar to the previously reported loss of neural crest and primary neuron fates induced by FoxD1 antimorph protein (Mariani and Harland, 1998). Previous studies showed that FoxD1 is initially expressed in mesoderm tissue fated for dorsal-lateral and dorsal mesoderm fates such as muscle and notochord; ectopic FoxD1 expression increased muscle marker expression in embryos (Gómez-Skarmeta et al., 1999). As detected by RT-PCR, FoxD1 morphant neurula stage embryos

A

Fig. 5. FoxD1 patterns mesoderm downstream to BMP antagonism. (A) Embryos were injected marginally at the one-cell stage with mRNA encoding foxd1 (25 pg) protein. VMZ explants were removed from control and injected embryos at early gastrula stage 10.25 and grown to neurula stage 17. Total RNA was isolated from five control embryos (lane 2) and eighteen VMZs from each group (lanes 3-4). Various mesoderm markers along the DV axis were examined by sqRT-PCR: dorsall notochord (chd, xnot), dorsal/ lateral muscle (myod, MA) and ventral (vent1). (B) Embryos were co-injected marginally at the one-cell stage with the FoxD1-MO (25 ng) or mRNAs encoding the foxd1 (25 pg), noggin (20 pg), or dkk1 (35 pg) proteins. VMZ or DLMZ explants were removed from control and injected embryos at early gastrula stage 10.25 and grown to neurula stage 17. Explant elongations were scored as previously described, from three independent experiments for all explant groups: control VMZ ( $n=42), V M Z$-FoxD1 $(n=51), V M Z-N o g g i n(n=51), V M Z$ Noggin + FoxD1-MO $(n=52), V M Z-D k k 1 \quad(n=51), V M Z-F o x D 1+D k k 1(n=27)$, control DLMZ (n=54), DLMZ + FoxD1-MO ( $n=47)$. (C) Embryos were injected marginally at the one-cell stage with the FoxD1-MO (25 ng). VMZ explants were removed from control and FoxD1 morphant embryos at gastrula stage 10.25 and VMZs were cultured in soluble noggin to neurula stage 17. Total RNA was isolated from six control (lane 2) and FoxD1 morphant embryos (lane 3), and from eighteen VMZs from each group (lanes 4-7). Expression of dorsal, dorsal-lateral, and ventral markers was examined by sqRT-PCR: chd, xnot, foxd1, myod, MA and vent1. odc serves as a control for quantitating RNA levels. (D) Embryos were injected marginally at the one-cell stage with the FoxD1-MO (25 pg) or mRNA encoding noggin protein. DLMZ explants were removed from control and injected embryos at gastrula stage 10.25, and DLMZs were cultured in soluble noggin to neurula stage 17. Total RNA was isolated from six control embryos (lane 2), and from eighteen DLMZs from each group (lanes 3-5). Expression of the anterior (nkx2.5), dorsal (xnot, chd), and dorsal lateral (MA) markers was examined by sqRT-PCR. have sharp reduction in dorsal notochord (xnot) and dorsal-lateral muscle (myod and muscle actin - MA) cell fates (Fig. 4B, 5C), with a concomitant increase in the ventrally expressed wnt8, vent2, and vent 1 markers (Fig. 4B, lane 2 versus 3). As seen by in situ hybridization, at gastrula stages, expression of the muscle and notochord dorsal lateral markers myod, and chd, are severely reduced in FoxD1 morphants (Fig. 4C). At later neural stages, we also see a reduction in notochord markers such as, chordin and xnot (not shown), and muscle markers such as myod (not shown) and MA (Fig. 4D). Typically, notochord markers are less dramatically reduced versus muscle markers. Ectopic FoxD1VP16 antimorph protein inhibited neural marker expression in Xenopus embryos (Mariani and Harland, 1998). Similar to the FoxD1-MO, ectopic FoxD1-VP16 antimorph protein also reduced expression levels of dorsal mesoderm markers in gastrula (not shown) and neurula stage embryos (Fig. 4E). As a control for FoxD1-MOspecificity, we demonstrate that ectopically expressed FoxD1 protein can rescue the loss of myod and ncam expression in FoxD1 morphant embryos (Fig. 4F).

Explant elongation

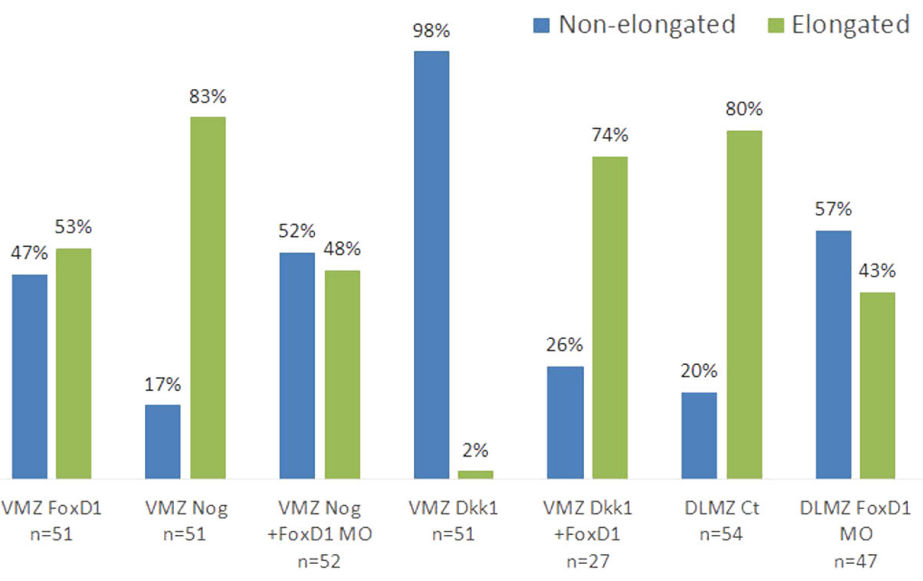

D
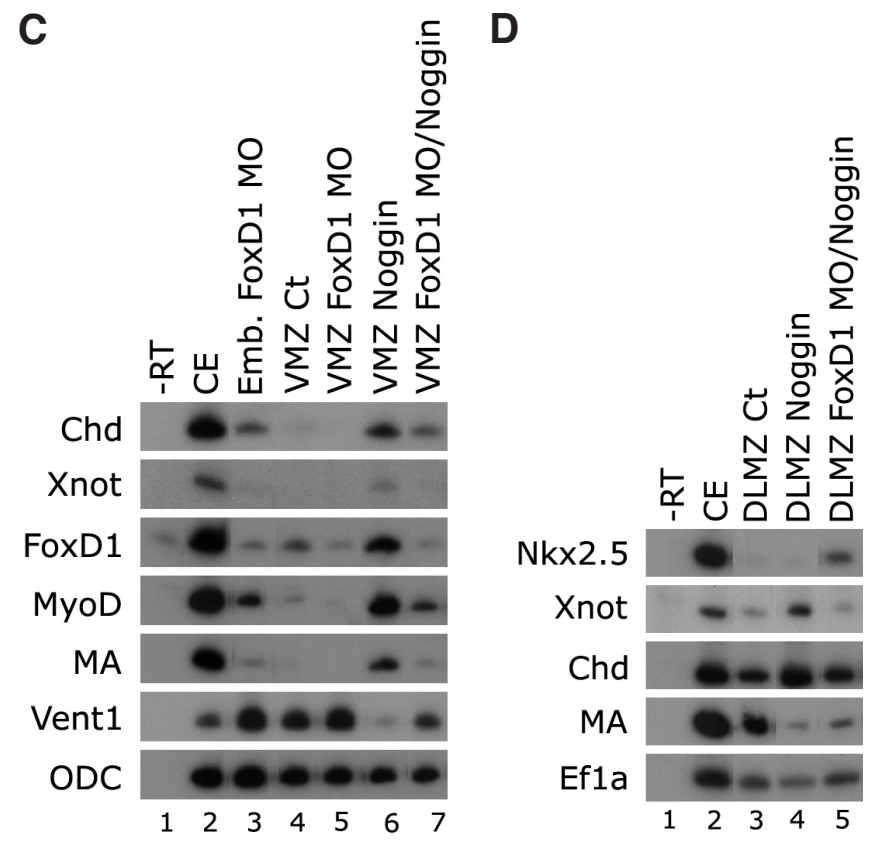


\section{FoxD1 has differential roles in dorsal-ventral mesoderm patterning}

This reduction in notochord and muscle formation is the first known mesodermal knockdown phenotype for FoxD1 protein in Xenopus. To further elucidate the role of FoxD1 in mesoderm patterning, we investigated its interactions with either BMP or canonical Wnt signaling pathways in early stage mesoderm explants. FoxD1 is expressed at high levels in the dorsal and dorsal-lateral marginal zone (DMZ, DLMZ) regions in gastrula stage embryos (Gómez-Skarmeta et al., 1999; not shown), but not in the ventral marginal zone (VMZ). To address a role for FoxD1 in mesoderm dorsalization, we ectopically expressed FoxD1 protein in VMZ explants. FoxD1 induced expression of both muscle (muscle actin-MA, myod) and notochord (xnot, chd) markers in these explants (Fig. 5A). Expression of the ventral marker vent1 was repressed by ectopic FoxD1 activity (Fig. 5A). These VMZexplants also underwent convergent extension elongations characteristic of dorsal muscle and notochord, but not ventral tissue (Fig. 5B). The ectopic activation of notochord and muscle markers and the induced explant elongations demonstrates that FoxD1 protein re-specifies ventral tissue to dorsal fates.

During gastrula stages, BMP antagonists secreted from the DMZ dorsalize ventral mesoderm to dorsal-lateral fates like muscle (Harland and Gerhart, 1997; De Robertis et al., 2000). Noggin treatment of VMZ explants induces muscle formation and convergent extension (Smith et al., 1993; Re'em-Kalma et al., 1995). Analogous to Noggin treated ACs (Mariani and Harland, 1998), foxd1 gene expression is also induced in Noggin dorsalized VMZs (Fig. 5C, lane 4 versus 6 ). To address a role for FoxD1 in this dorsalizing assay, the FoxD1-MO was injected into Noggin treated VMZs. In these explants, there was a strong reduction in the induction of muscle and notochord marker expression (Fig. 5C, lane 6 versus 7) and a reduction in explant elongations (Fig. 5B). Endogenous FoxD1 protein is also required for Noggin to activate foxd1 gene expression (Fig. 5C, lane 6 versus 7). In parallel, the FoxD1-MO increased expression of ventral markers (vent1, wnt8) in the VMZs (Fig. 5C, lane 4 versus 5 , lane 6 versus 7), suggesting that endogenous levels of FoxD1 protein act in the mesoderm to actively repress ventral cell fates at the dorsal-lateral/ventral border regions. FoxD1 protein acts
A

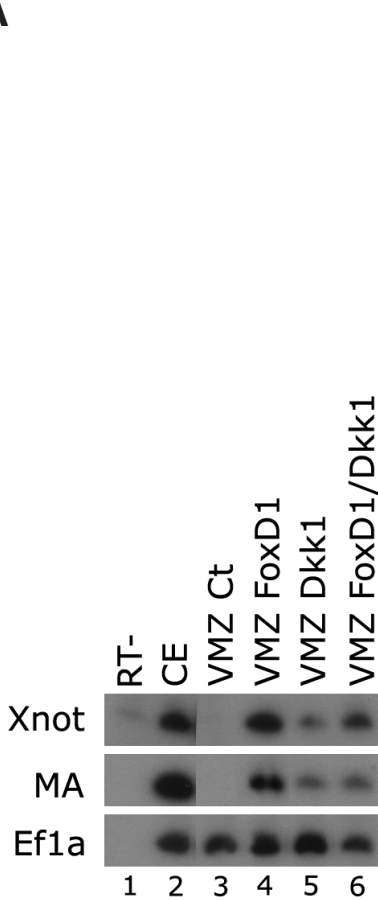

B

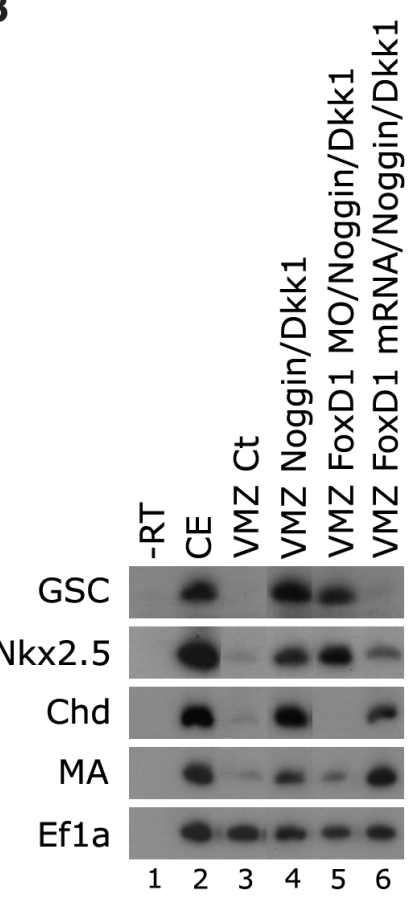

C

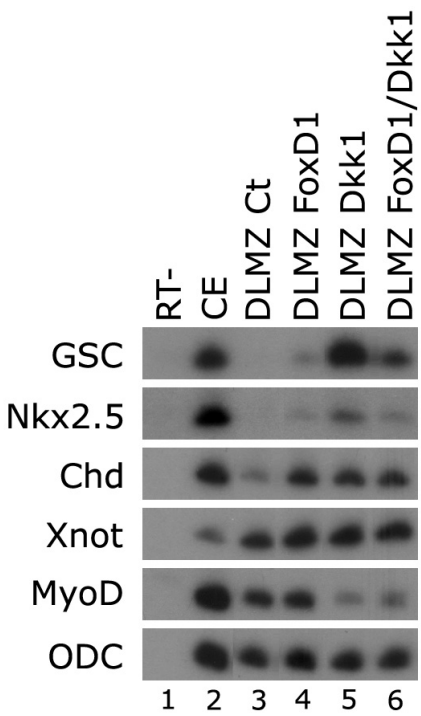

D

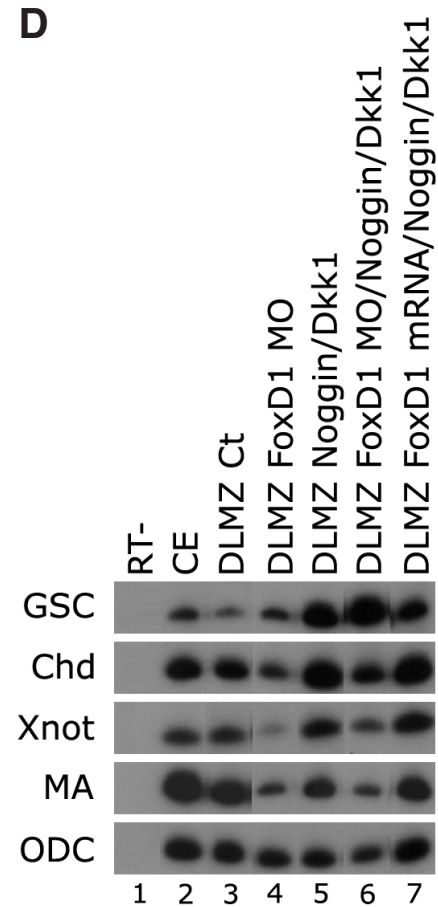

Fig. 6. FoxD1 and Wnt signaling interact to pattern dorsal mesoderm. (A) Embryos were injected marginally at the one-cell stage with mRNA encoding the foxd1 (25 pg) or dkk1 (40 pg) protein. VMZ explants were removed from control and injected embryos at gastrula stage 10.25, and VMZs were cultured to neurula stage 17. Total RNA was isolated from six control embryos (lane 2), and from eighteen VMZs from each group (lanes 3-6). Expression of the xnot and MA markers was examined by sqRT-PCR. (B) Embryos were injected marginally at the one-cell stage with mRNA encoding the noggin (20 pg) and dkk1 (40 pg) proteins. Embryos were than co-injected with either mRNA encoding the foxd1 (30 pg) protein or the FoxD1-MO (45 pg). VMZ explants were removed from control and injected embryos at gastrula stage 10.25, and VMZs were cultured to neurula stage 17. Total RNA was isolated from six control embryos (lane 2), and from eighteen DLMZs from each group (lanes 3-6). Expression of the anterior (gsc, nkx2.5), dorsal (chd), and dorsal lateral (MA) markers was examined by sqRT-PCR. (C) Embryos were injected marginally at the one-cell stage with mRNA encoding the foxd1 (25 pg) and dkk1 (40 pg). DLMZ explants were removed from control and injected embryos at gastrula stage 10.25, and cultured to neurula stage 17. Total RNA was isolated from six control embryos (lane 2), and from eighteen DLMZs from each group (lanes 3-6). Expression of the anterior (gsc,nkx2.5), dorsal (chd, xnot), and dorsal lateral (myod) markers was examined by sqRT-PCR. (D) Embryos were injected marginally at the one-cell stage with mRNA encoding the noggin (20 pg) and dkk1 (40 pg) proteins. Embryos were than co-injected with either mRNA encoding the foxd1 (30 pg) protein or the FoxD1-MO (45 pg). DLMZ explants were removed from control and injected embryos at gastrula stage 10.25, and DLMZs were cultured to neurula stage 17. Total RNA was isolated from six control embryos (lane 2), and from eighteen DLMZs from each group (lanes 3-7). Expression of the anterior (gsc), dorsal (chd, xnot), and dorsal lateral (MA) markers was examined by sqRT-PCR. 
downstream to BMP antagonism to regulate dorsal mesoderm formation. Similar results were seen in noggin treated DLMZ explants. Noggin reduced muscle but increased more dorsal notochord marker expression in these explants (Fig. 5D, lane 3 versus 4) The FoxD1-MO strongly reduced noggin induction of notochord marker expression (Fig. 5D, lane 4 versus 5). In noggindorsalized DLMZs, FoxD1 knockdown triggered expression of the more anterior heart specific $n k x 2.5$ marker (Fig. 5D, lane 5) suggesting that in dorsal mesoderm, FoxD1 actively represses expression of genes that promote more anterior heart fates. In further support, FoxD1 morphant DLMZs undergo significantly less elongation versus control DLMZs (Fig. 5B), likely due to the loss of muscle and notochord fates.

\section{FoxD1 and Wnt signaling interact to regulate dorsal-ventral mesoderm patterning}

In Xenopus and other vertebrates, early zygotic Wnt signaling has been shown to be required for muscle formation (Christian and Moon, 1993; Hoppler et al., 1996; Hoppler and Moon, 1998; Lekven et al., 2001). Wnt8 is expressed in the most ventral mesoderm (Smith and Harland, 1991), and Wnt antagonists are expressed in the more dorsal-anterior regions (Cruciat and Niehrs, 2013), suggesting that in the DLMZ, an intermediate level of Wnt signaling is required for muscle formation. We determined if FoxD1 requires Wnt signaling to induce dorsal cell fates. FoxD1 and the canonical Wnt inhibitor Dkk1 were co-expressed in VMZs. In this assay FoxD1 poorly induces muscle and notochord markers (Fig. 6A); however, notochord markers tend to be less inhibited than muscle markers, since muscle specification is more sensitive to the loss of Wnt-signaling than the more dorsal notochord. Unlike noggin, which dorsalizes the VMZ, Dkk1 alone does not significantly dorsalize or anteriorize VMZ cell fates (Fig. 6A) nor induce elongation movements (Fig. 5B). To further address this point, VMZs were dorso-anteriorized by the ectopic co-expression of both Noggin and Dkk1 proteins. Under these conditions, the more anterior gsc and $n k x 2.5$ markers were expressed along with muscle and notochord markers (Fig 6B, lane 3 versus 4). The gsc gene is expressed in the most anterior prechordal mesoderm and is only expressed in VMZ and DLMZ explants when Wnt signaling is inhibited by Dkk1 protein expression (Figs. 6 B-D). When these anteriorized explants are knocked down for FoxD1 protein by the FoxD1-MO, nkx2.5 and gsc expression is increased, or maintained at high levels, yet $c h d$ and $M A$ levels are reduced (Fig. 6B, lane 4 versus 5). Reciprocally, when ectopic FoxD1 protein was expressed in these anteriorized explants, chd and $M A$ was increased, but $g s c$ and $n k x 2.5$ expression were strongly inhibited (Fig. 6B, lane 4 versus 6). These results again suggest that FoxD1 maintains muscle and notochord fates by repressing both anterior and ventral fates (Fig. 4B, 5 A-C).

To gain a more thorough understanding of the role of FoxD1/ Wnt signaling interactions in mesoderm patterning, we performed experiments on DLMZ explants fated for notochord and muscle that were anteriorized by ectopic Dkk1 protein expression. Unlike VMZs, DLMZs are specified to dorsal fates. In the DLMZs, ectopic FoxD1 protein expression enhanced notochord marker expression, but had a less profound effect on muscle markers, presumably because muscle is at saturation levels in the DLMZ, whereas notochord is not (Fig. 6C, lane 3 versus 4). Ectopic Dkk levels enhanced expression of the more anterior pre-chordal gsc and heart $n k x 2.5$ markers; notochord markers were also increased, but muscle marker expression was reduced (Fig. 6C, lane 3 versus 5). Co-expression of FoxD1 and Dkk1 proteins caused a reduction in anterior marker expression, notochord markers were maintained, but muscle marker expression was not rescued (Fig. 6C, lane 5 versus 6 ). Inhibition of Wnt signaling is permissive for the most anterior and dorsal fates, but not for the more lateral muscle. Ectopic levels of FoxD1 and Dkk1 proteins inhibited anterior marker expression, maintained notochord levels, but could not rescue muscle fates, due to low Wnt signaling. Thus in the DLMZ, FoxD1 can maintain notochord cell fates, but not muscle cell fates in the absence of Wnt signaling.

To further elucidate FoxD1/Wnt signaling interactions, DLMZ explants fated for notochord and muscle were dorso-anteriorized by ectopic co-expression of both Noggin and Dkk1 proteins (Fig. 6D). In the DLMZs, FoxD1 protein knock down, enhances basal levels of $g s c$ expression, while reducing expression of notochord and muscle markers (Fig. 6D, lane 3 versus 4). Ectopic levels of Noggin and Dkk1 proteins strongly increased gsc levels, moderately increased chd and xnot levels, while MA levels are slightly reduced (Fig. 6D, lane 3 versus 5). Noggin and Dkk1 push mesoderm cells to more dorsal-anterior fates (prechordal and notochord), away from the more lateral muscle. When FoxD1 protein is knocked down, gsc expression is further enhanced, while notochord and muscle markers are reduced (Fig. $6 \mathrm{D}$, lane 5 versus 6 ). In contrast, when FoxD1 protein is ectopically expressed, gsc expression is reduced and notochord and muscle markers are increased (Fig. 6D, compare lane 5 versus 7). Interestingly in a manner similar to the anterior gsc marker residual expression levels of the vent 1 gene in DLMZ explants were further repressed by ectopic FoxD1 protein expression and increased by FoxD1 protein knockdown (not shown). These results again demonstrate how FoxD1 protein actively represses both anterior and ventral mesoderm fates, while simultaneously promoting dorsal and dorsal-lateral and cell fates.

\section{Discussion}

There are over forty different forkhead box/Fox genes in the vertebrate genome. This gene family is subdivided into 19 subfamilies, A - S, based amino acid variations within the forkhead box domain (Yaklichken et al., 2007; Shimeld et al., 2010). These proteins play diverse roles in early vertebrate development, and Fox gene family mutations have also been associated with a number of human genetic diseases (Hannenhalli and Kaestner, 2009; Benayoun et al., 2011). These proteins have a highly conserved Fox helix-turn-helix DNA binding site, but are poorly conserved outside this Fox domain. Fox family proteins interact with a large number of different proteins that regulate gene expression, mainly acting as transcriptional repressors, but Fox proteins also act as activators in some cellular contexts (Yaklichken et al., 2007; Benayoun et al., 2011).

In chick and mouse embryos, FoxD1 protein regulates kidney organogenesis (Hatini et al., 1996; Levinson et al., 2005; Fetting et al., 2014), and retina formation (Herrera et al., 2004; Takahashi et al., 2009; Carreres et al., 2011). In Xenopus laevis embryos, FoxD1 protein regulates early nervous system specification and patterning (Mariani and Harland, 1998). During early Xenopus development, the foxd1 gene is expressed in gastrula stage 
dorsal mesoderm fated for muscle and notochord. Only at later neurula stages does foxd1 gene expression become restricted to anterior forebrain neural tissue (Mariani and Harland, 1998; Gómez-Skarmeta et al., 1999). Little was known about FoxD1 mesoderm function, except that ectopic expression of FoxD1 protein increased muscle marker levels in Xenopus embryos (Gómez-Skarmeta et al., 1999). At later stages, FoxD1 functions as a transcriptional repressor in Xenopus, to mediate neural induction and patterning downstream of BMP antagonism (Mariani and Harland, 1998). The FoxD1 antimorph protein prevented neural tissue formation in Xenopus embryos and wild type or antimorph protein over expression reciprocally neuralized embryos (Mariani and Harland, 1998). Somewhat surprisingly, in naïve AC ectoderm assays, ectopic FoxD1 not only induced expression of panneural and anterior neural markers, but also induced expression of more posterior hindbrain and spinal cord markers (Wallingford and Harland, 2001; Borchers et al., 2008; Fonar et al., 2011). Moreover, these explants undergo neural convergent extension morphogenesis characteristic of hindbrain and spinal cord cells (Wallingford and Harland, 2001; Borchers et al., 2008; Fonar et al., 2011). FoxD1 activates wnt3a gene expression in ACs, which appears to be required for the induction of posterior neural markers (Fonar et al., 2011).

Zygotic canonical Wnt signaling regulates neural AP and mesodermal dorso-ventral (DV) patterning events during early development (Kimelman, 2006; Elkouby and Frank, 2010). Since the foxd1 gene is expressed in early mesoderm and neural tissues, we examined the interaction between FoxD1 protein and Wnt signaling in regulating both neural AP and mesodermal DV patterning. Our initial observation found that in embryos lacking canonical Wnt signaling (ectopic Dkk1 expression) that co-express FoxD1 protein, there was a strong neural anteriorization phenotype that was markedly more extreme than embryos expressing either ectopic FoxD1 or Dkk1 protein alone. This result suggests that in a Wnt-depleted environment, FoxD1 acts more strongly to induce anterior neural tissue. This observation was further confirmed in AC explants. In ACs co-expressing FoxD1 and Dkk1 proteins, there was a sharp increase in anterior neural marker expression, with a parallel decrease in posterior neural marker expression, versus ACs solely expressing ectopic FoxD1. This result suggests that FoxD1 only activates posterior neural markers in regions where canonical Wnt activity is high. This ability of FoxD1 to induce posterior neural markers was uncoupled from its neural inducing activity. In the presence of ectopic BMP activity that inhibits neural induction (blocking panneural and anterior neural marker expression), FoxD1 induced expression of hindbrain and spinal cord markers. Under these conditions, FoxD1 enhanced spinal cord marker expression in the presence of BMP signaling. This uncoupling of "general" neural induction from posterior neural induction/patterning has been shown for other neural caudalizing proteins, like Wnt3a and Meis3 in naïve ACs (Salzberg et al., 1999; Elkouby et al., 2010). In reciprocal experiments in ACs co-expressing FoxD1 and Wnt3a proteins, anterior neural marker expression is sharply decreased, with a parallel increase in posterior neural marker expression versus ACs solely expressing ectopic FoxD1. However, in Xenopus embryos, normal foxd1 expression is restricted to the forebrain region, where BMP and Wnt signaling levels are at their lowest (Fig. 7B), being repressed by endogenous antagonist proteins (Niehrs et al., 2001). Thus, the FoxD1 protein can multitask to pattern neural tissue along the AP axis. However under the physiological restraints of its normal rostral expression domain, it will act as a neural anteriorizer. Yet, if given the proper non-physiological environment, with high Wnt levels, FoxD1 neural caudalizing activity is unmasked.

Analogous observations were seen for an earlier role of FoxD1 protein in dorsal mesoderm specification and patterning. Similar to anterior neural tissue, FoxD1 expression is activated by BMP antagonists and FoxD1 is required downstream to BMP antagonism for proper muscle and notochord formation. In FoxD1 morphant embryos, there is a sharp loss of both muscle and notochord cell
A

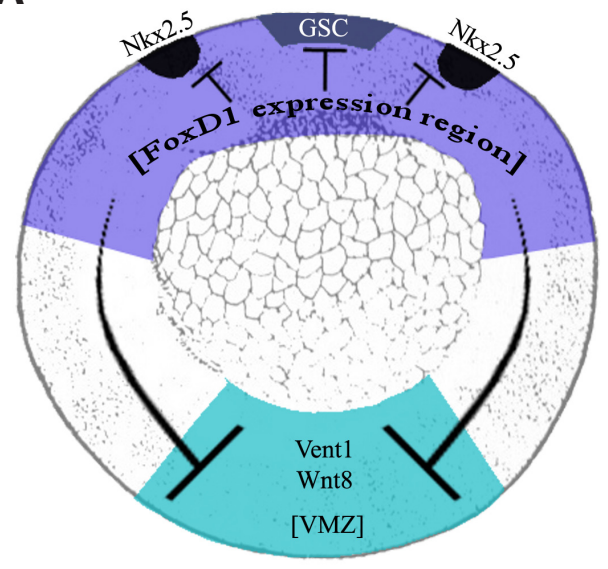

B

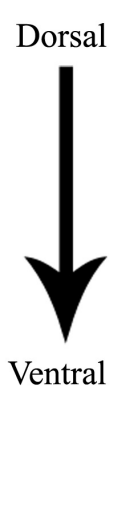

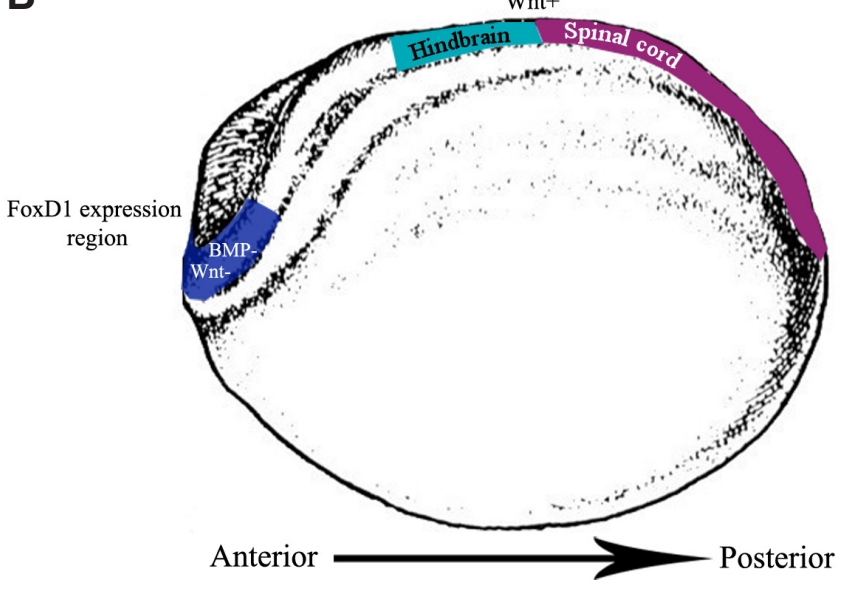

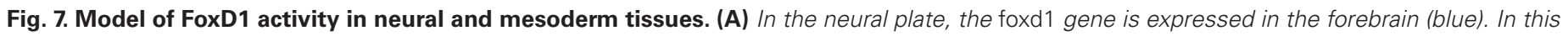

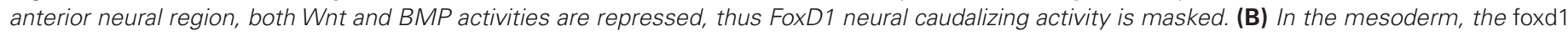

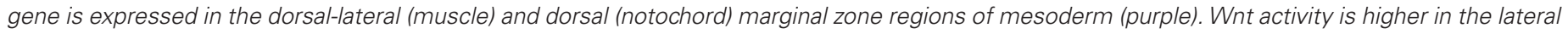

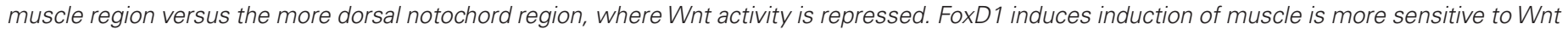

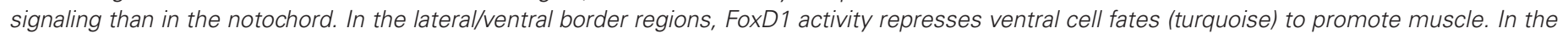
dorsal regions, FoxD1 activity represses anterior heart (black) and prechordal (grey) mesoderm to promote muscle notochord. 
fates. However, unlike FoxD1 forebrain inducing activity in the nervous system which acts independently of Wnt signaling, Wnt activity is required for FoxD1 regulation of muscle formation in the mesoderm. Thus in addition to BMP antagonism, canonical Wnt signaling acts with FoxD1 protein to induce muscle. This requirement for Wnt signaling is not as strict for regulation of the more dorsal notochord tissue. In addition to promoting muscle and notochord cell fates, FoxD1 also functions to repress cell fates in these regions. In more ventral regions, in the DLMZ/VMZ border region, where Wnt signaling is higher and required for muscle formation, FoxD1 acts to repress ventral cell fates (Fig. 7B). In the more dorsal/anterior border regions, where Wnt signaling is low, FoxD1 represses anterior fates (prechordal, heart) to promote notochord formation (Fig 7B).

Thus in the mesoderm, FoxD1 acts downstream to BMP antagonism and utilizes varying Wnt levels to direct cells to different fates along the antero-posterior and dorso-ventral axes. FoxD1 acts as a multifunctional protein that interacts differentially to its cellular signaling environment to "fine tune" and promote cell fates in the different germ layers. In neural tissue, its global activity, which includes activating posterior cell fates via wnt3a gene activation (Fonar et al., 2011), is restricted to anterior neuralizing activity, because in vivo, the protein is expressed in a low-Wnt, low-BMP embryonic regions. In the mesoderm, the FoxD1 is expressed in regions with varying Wnt levels and low BMP activities, where it differentially promotes dorsal mesoderm fates, while repressing ventral and anterior fates.

We have not pinpointed if FoxD1 is directly modifying Wnt or BMP target genes, or whether its effects are more indirect. Fox proteins do interact with the Groucho repressor protein, and Groucho directly interacts with the transcriptional machinery mediating the Wnt and Nodal signaling pathways (Daniels and Weis, 2005, Yaklichken et al., 2007, Reid et al., 2016). In the absence of Wnt signaling, FoxD1 proteins could potentially be part of a complex directly repressing Wnt target genes in anterior neural or dorsal mesodermal regions. Another possibility is that the activation/ antagonism of Wnt or BMP signaling modifies the accessibility of FoxD1 protein to different chromatin domains, thus modulating its ability to repress varying target genes in specific tissues. Future experiments should determine how FoxD1 protein mediates repression of gene expression in differing signaling environments.

Our results show that the FoxD1 protein has a number of intrinsic activities that direct cell fate decisions, but they are tightly regulated by the localized signaling cues active in its region of expression. In theory, a transcription factor can have many latent activities that are only partially released in certain cellular contexts. This mode of activity could explain diverse functions for a given protein at the same developmental time, but in different tissues, for different times of development in the same organism, or even differences in function for the same protein between different species. Varying transcription factor activity as a function of a localized signaling environment could be a strong evolutionary factor that drives differential functions of the same transcription factor in a wide variety of tissues and species. Essentially, the specific signaling environment in a transcription factor expression domain will determine which intrinsic function will be activated or masked. FoxD1 is a prime example of how this intricate regulation is utilized for patterning of the nervous system and mesoderm during early Xenopus development.

\section{Materials and Methods}

\section{Xenopus embryos}

Ovulation, in vitro fertilization, culture, and explant dissections and treatments were as described (Re'em-Kalma et al., 1995; Henig et al., 1998; Bonstein et al., 1999). Explant elongations were quantitated as described (Bin-Nun et al., 2014).

\section{RNA, morpholino oligonucleotide (MO) injections, and plasmid constructs}

Capped sense in-vitro transcribed mRNA constructs of foxd1, VP16FoxD1 (Mariani et al., 1998), bmp4 (Re'em-Kalma et al., 1995), dkk, wnt3a, and noggin, (Elkouby et al., 2010; Elkouby et al., 2012) were injected into one-cell stage embryos. The sequence of the FoxD1 antisense morpholino oligonucleotide (FoxD1-MO) is: 5'-TCATGGCTTGGGAGGCAAAGCATAA-3', (Gene Tools).

\section{In-situ hybridization}

Whole-mount in-situ hybridization was performed with digoxigeninlabeled probes (Harland, 1991) to muscle actin (MA) and myod (Keren et al., 2005), chd (Murgan et al., 2014), and otx2, krox20 and hoxb9 (Aamar and Frank, 2004; Gutkovich et al., 2010).

\section{Semi-quantitative (sq) RT-PCR analysis}

sqRT-PCR was performed (Snir et al., 2006). In all sqRT-PCR experiments, three to six independent experimental repeats were typically performed. In all experiments, samples are routinely assayed a minimum of two times for each marker. sqRT-PCR Primers: efa, odc, his4, nrp1, ncam, xanf1, otx2, xag1, krox20, gbx2, hoxb9, cdx1, cdx4, n-tub, gsc, nkx2.5, chd, $x n o t$, foxd1, myod, muscle actin (MA), vent1, vent2, wnt8 (Zetser et al., 2001; Dibner et al., 2004; Snir et al., 2006; Gutkovich et al., 2010; Elkouby et al., 2010, Fonar et al., 2011, Bin-Nun et al., 2014).

\section{Acknowledgments}

We thank Drs. R. Harland and C. Niehrs for plasmids. D.F. was supported by grants from the Israel-Niedersachsen Fund (ZN2319) and the Israel Science Foundation (658/09, 658/15).

\section{References}

AAMAR, E., FRANK, D. (2004). Xenopus Meis3 protein forms a hindbrain-inducing center by activating FGF/MAP kinase and PCP pathways. Development 131: 153-163.

BENAYOUN, B.A., CABURET, S., VEITIA, R.A. (2011). Forkhead transcription factors: key players in health and disease. Trends Genet. 2011 27: 6, 224-232.

BIN-NUN, N., LICHTIG, H., MALYAROVA, A., LEVY, M., EILIAS, S. and FRANK, D. (2014). PTK7 modulates Wnt signaling activity via LRP6. Development 141: 410-421.

BONSTEIN, L., ELIAS, S., FRANK, D. (1998). Paraxial fated mesoderm is required for neural crest induction in Xenopus embryos. Dev. Biol. 193: 156-168.

BORCHERS, A., FONAR, Y., FRANK, D., BAKER, J.C. (2006). XNF-ATc3 affects neural convergent extension. Development 133: 1745-1755.

CARRERES, M.I., ESCALANTE, A., MURILlO, B., CHAUVIN, G., GASPAR, P., VEGAR, C., HERRERA, E. (2011). Transcription factor Foxd1 is required for the specification of the temporal retina in mammals. J Neurosci. 31: 5673-5681.

CHRISTIAN, J.L., MOON, R.T. (1993). Interactions between Xwnt-8 and Spemann organizer signaling pathways generate dorsoventral pattern in the embryonic mesoderm of Xenopus. Genes Dev. 7: 13-28.

CRUCIAT, C.M., NIEHRS, C. (2013). Secreted and transmembrane wnt inhibitors and activators. Cold Spring Harb. Perspect. Biol. 5: a015081.

DANIELS D.L., WEIS, W.I. (2005). Beta-catenin directly displaces Groucho/TLE repressors from Tcf/Lef in Wnt mediated transcription activation. Nat Struct Mol Biol. 12: 364-371.

DE ROBERTIS, E.M., LARRAIN, J., OELGESCHLAGER, M., WESSELY, O. (2000). 
The establishment of Spemann's organizer and patterning of the vertebrate embryo. Nat. Rev. Genet 3: 171-181.

DIBNER, C., ELIAS, S., FRANK, D. (2001). XMeis3 protein activity is required for proper hindbrain patterning in Xenopus laevis embryos. Development 128: 3415-3426.

DIBNER, C., ELIAS, S., OFIR, R., SOUOPGUI, J., KOLM, P.J., SIVE, H., PIELER, T., FRANK, D. (2004). The Meis3 protein and retinoid signaling interact to pattern the Xenopus hindbrain. Dev. Biol. 271: 75-86.

ELKOUBY, Y.M., ELIAS, S., CASEY, E.S., BLYTHE, S.A., TSABAR, N., KLEIN, P.S., ROOT, H., LIU, K.J., FRANK, D. (2010). Mesodermal Wnt signaling organizes the neural plate via Meis3. Development 137: 1531-1541.

ELKOUBY, Y.M., FRANK, D. (2010). Wnt//-catenin signaling in vertebrate posterior neural development. In Colloquium Series on Developmental Biology (ed. D. S. Kessler), eBook 4. San Rafael, CA. Morgan \& Claypool Life Sciences.

ELKOUBY, Y.M., POLEVOY, H., GUTKOVICH, Y.E., MICHAELOV, A., FRANK, D. (2012) A hindbrain-repressive Wnt3a/Meis3/Tsh1 circuit promotes neuronal differentiation and coordinates tissue maturation. Development 139: 1487-1497.

FETTING, J.L., GUAY, J.A., KAROLAK, M.J., IOZZO, RV, ADAMS, D.C., MARIDAS, D.E., BROWN, A.C., OXBURGH, L. (2014). FOXD1 promotes nephron progenitor differentiation by repressing decorin in the embryonic kidney. Development 141: 1-11.

FONAR, Y., GUTKOVICH, Y.E., ROOT, H., MALYAROVA, A., AAMAR, E., GOLU BOBSKAYA, V.M., ELIAS, S., ELKOUBY, Y.M., FRANK, D. (2011). Focal adhesion kinase protein regulates Wnt3a gene expression to control cell-fate specification in the developing neural plate. Mol. Biol. Cell 22: 2409-2421.

GERHART, J. (2015). Cellular Basis of Morphogenetic Change: Looking Back after 30 Years of Progress on Developmental Signaling Pathways Springer Science + Business Media Dordrecht. A.C. Love (ed.), Conceptual Change in Biology, Boston Studies in the Philosophy and History of Science 307, Chapter 8, 175-197.

GOMEZ-SKARMATA, J.L., DE LACALLE-MUSTIENES, E., MODOLELL, J., MAYOR, R. (1999). Xenopus brain factor-2 controls mesoderm, forebrain and neural crest development. Mech. Dev. 80: 15-27.

GUTKOVICH, Y.E., OFIR, R., ELKOUBY, Y.M., DIBNER, C., GEFEN, A., ELIAS, S., FRANK, D. (2010). Xenopus Meis3 protein lies at a nexus downstream to Zic1 and Pax3 proteins, regulating multiple cell-fates during early nervous system development. Dev. Biol. 338: 50-62.

HANNENHALLI, S., KAESTNER, K.H. (2009). The evolution of Fox genes and their role in development and disease. Nat. Rev. Genet. 10: 233-240.

HARLAND, R.M. (1991). In situ hybridization: an improved whole-mount method for Xenopus embryos. Methods Cell Biol. 36: 685-695.

HARLAND, R., GERHART, J. (1997). Formation and function of Spemann's organizer. Annu. Rev. Cell Dev. Biol. 13: 611-667

HATINI, V., HUH, S.O., HERZLINGER, D., SOARES, V.C., LAI, E. (1996). Essential role of stromal mesenchyme in kidney morphogenesis revealed by targeted disruption of Winged Helix transcription factor BF-2. Genes Dev. 10: 1467-1478.

HENIG, C., ELIAS, S., FRANK, D. (1998). A POU protein regulates mesoderm competence to FGF in Xenopus. Mech. Dev. 71: 131-142

HERRERA, E., MARCUS, R., LI, S., WILLIAMS, S.E., ERSKINE, L., LAI, E., MASON, C. (2004). Foxd1 is required for proper formation of the optic chiasm. Development 131: 5727-5739.

HOPPLER, S., BROWN, J.D., MOON, R.T. (1996). Expression of a dominant negative Wnt blocks induction of MyoD in Xenopus embryos. Genes Dev. 10: 2805-2817.

HOPPLER, S., MOON, R.T. (1998). BMP-2/-4 and Wnt-8 cooperatively pattern the Xenopus mesoderm. Mech. Dev. 71: 119-129.
KEREN, A., BENGAL, E, FRANK, D. (2005). p38 MAP kinase regulates the expression of XMyf5 and affects distinct myogenic programs during Xenopus development. Dev. Biol. 288: 73-86.

KIMELMAN, D. (2006). Mesoderm induction: from caps to chips. Nat. Rev. Genet. 7: $360-372$.

LEKVEN, A.C., THORPE, C.J., WAXMAN, J. S., MOON, R.T., R. T. (2001). Zebrafish wnt8 encodes two wnt8 proteins on a bicistronic transcript and is required for mesoderm and neurectoderm patterning. Dev. Cell 1: 103-114.

LEVINSON, R.S., BATOURINA, E., CHOI, C., VORONTCHIKHINA, M., KITAJEWSKI, J., MENDELSOHN, C.L. (2005). Foxd1-dependent signals control cellularity in the renal capsule, a structure required for normal renal development. Development 132: 529-539.

MARIANI, F.V., HARLAND, R.M. (1998). XBF-2 is a transcriptional repressor that converts ectoderm into neural tissue. Development 125: 5019-5031.

MURGAN, S., CASTRO COLABIANCHI, A.M., MONTI, R.J, BOYADJIAN LOPEZ, L.E., AGUIRRE, C.E., STIVALA E.G., CARRASCO, A.E., LOPEZ, S.L. (2014). FoxA4 favours notochord formation by inhibiting contiguous mesodermal fates and restricts anterior neural development in Xenopus embryos. PLoS One 9: e110559.

NIEHRS, C., KAZANSKYA, O., WU, W., GLINKA, A. (2001). Dickkopf1 and the Spemann-Mangold head organizer. Int. J. Dev. Biol. 45: 237-240

RE'EM-KALMA, Y., LAMB, T., FRANK, D. (1995). Competition between noggin and bone morphogenetic protein 4 activities may regulate dorsalization during Xenopus development. Proc. Natl. Acad. Sci. USA 92: 12141-12145.

REID, C.D., STEINER, A.B., YAKLICHKIN, S., LU, Q., WANG, S., HENNESSY, M., KESSLER, D.S. (2016). FoxH1 mediates a Grg4 and Smad2 dependent transcriptional switch in Nodal signaling during Xenopus mesoderm development. Dev. Biol. 414: 34-44.

SALZBERG, A., ELIAS, S., NACHALIEL, N., BONSTEIN, L., HENIG, C., FRANK, D. (1999). A Meis family protein caudalizes neural cell-fates in Xenopus. Mech. Dev. 80: 3-13.

SHIMELD, S.M., DEGNAN, B., LUKE, G.N. (2010). Evolutionary genomics of the Fox genes: origin of gene families and the ancestry of gene clusters. Genomics 95: 256-260

SMITH W.C., HARLAND, R.M. (1991). Injected Xwnt-8 RNA acts early in Xenopus embryos to promote formation of a vegetal dorsalizing center. Cell 67: 753-765.

SMITH W.C., KNECHT, A.K., WU, M., HARLAND, R.M. (1993). Secreted noggin protein mimics the Spemann organizer in dorsalizing Xenopus mesoderm. Nature 361: 547-549.

SNIR, M., OFIR, R., ELIAS, S., FRANK, D. (2006). Xenopus laevis POU91 protein an Oct3/4 homologue, regulates competence transitions from mesoderm to neural cell-fates. EMBO J. 25: 3664-3674

TAKAHASHI, H., SAKUTA, H., SHINTANI, T., NODA, M. (2009). Functional mode of FoxD1/CBF2 for the establishment of temporal retinal specificity in the developing chick retina. Dev. Biol. 331: 300-310.

WALLINGFORD, J.B., HARLAND, R.M. (2001). Xenopus Dishevelled signaling regulates both neural and mesodermal convergent extension: parallel forces elongating the body axis. Development 128: 2581-2592.

YALKICHKIN, S., VEKKER, A., STAYROOK, S., LEWIS, M., KESSLER, D.S. (2007) Prevalence of the $\mathrm{EH} 1$ Groucho interaction motif in the metazoan Fox family of transcriptional regulators. BMC Genomics 8: 201.

ZETSER, A., FRANK, D., BENGAL, E. (2001). MAP kinase converts MyoD into an instructive muscle differentiation factor in Xenopus. Dev. Biol. 240: 168-181. 


\section{Further Related Reading, published previously in the Int. J. Dev. Biol.}

The involvement of three signal transduction pathways in botryllid ascidian astogeny, as revealed by expression patterns of representative genes

Amalia Rosner, Gilad Alfassi, Elizabeth Moiseeva, Guy Paz, Claudette Rabinowitz, Ziva Lapidot, Jacob Douek, Abraham Haim and Baruch Rinkevich

Int. J. Dev. Biol. (2014) 58: 677-692

From Agrobacterium to viral vectors: genome modification of plant cells by rare cutting restriction enzymes Ira Marton, Arik Honig, Ayelet Omid, Noam De Costa, Elena Marhevka, Barry Cohen, Amir Zuker and Alexander Vainstein Int. J. Dev. Biol. (2013) 57: 639-650

What Hydra can teach us about chemical ecology - how a simple, soft organism survives in a hostile aqueous environment Tamar Rachamim and Daniel Sher

Int. J. Dev. Biol. (2012) 56: 605-611

Analysis of chemotaxis when the fraction of responsive cells is small - application to mammalian sperm guidance Anna Gakamsky, Edna Schechtman, S. Roy Caplan and Michael Eisenbach

Int. J. Dev. Biol. (2008) 52: 481-487

Mouse models to study inner ear development and hereditary hearing loss Lilach M. Friedman, Amiel A. Dror and Karen B. Avraham

Int. J. Dev. Biol. (2007) 51: 609-631

The importance of the posterior midline region for axis initiation at early stages of the avian embryo

Oded Khaner

Int. J. Dev. Biol. (2007) 51: 131-137

Early stages of neural crest ontogeny: formation and regulation of cell delamination Chaya Kalcheim and Tal Burstyn-Cohen

Int. J. Dev. Biol. (2005) 49: 105-116

Allogeneic interactions in Hydractinia: is the transitory chimera beneficial? Sharon Gild, Uri Frank and Ofer Mokady

Int. J. Dev. Biol. (2003) 47: 433-438

High proliferation rate characterizes the site of axis formation in the avian blastula-stage embryo.

N Zahavi, V Reich and O Khaner Int. J. Dev. Biol. (1998) 42: 95-98
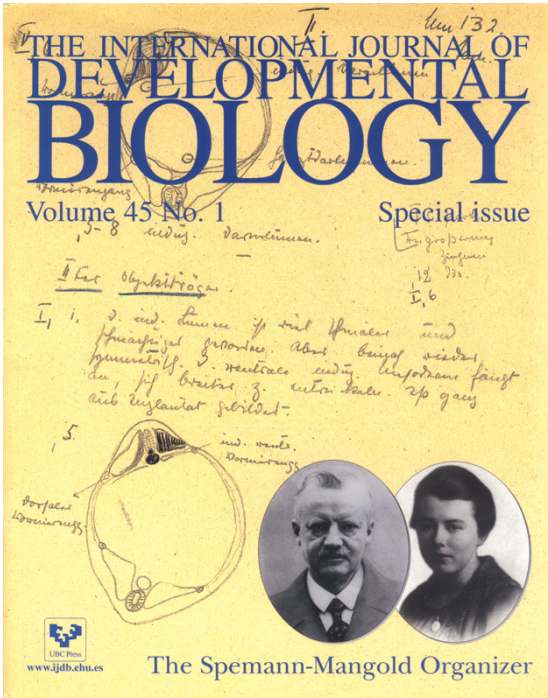

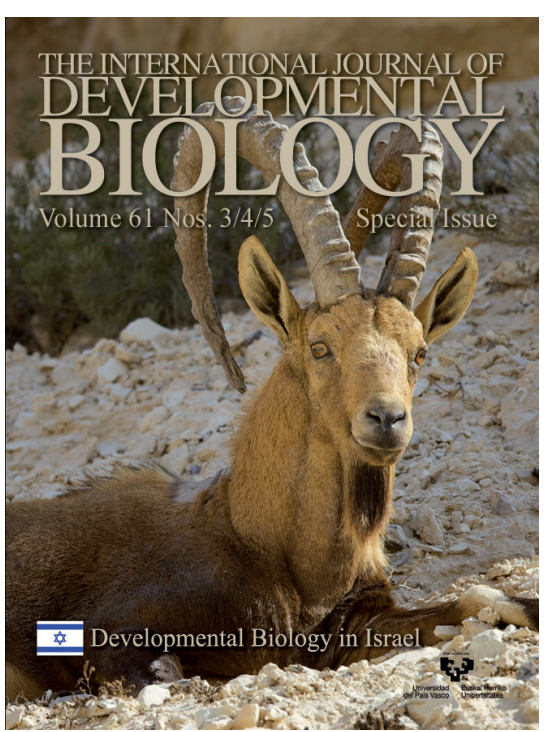

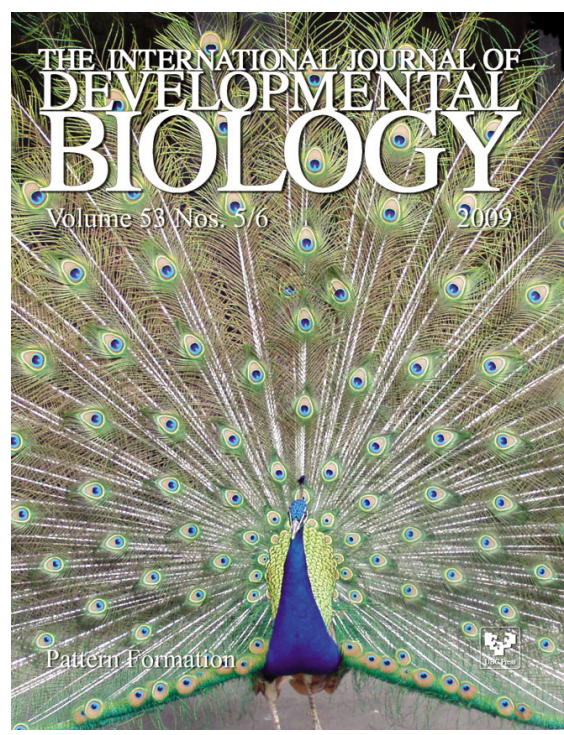

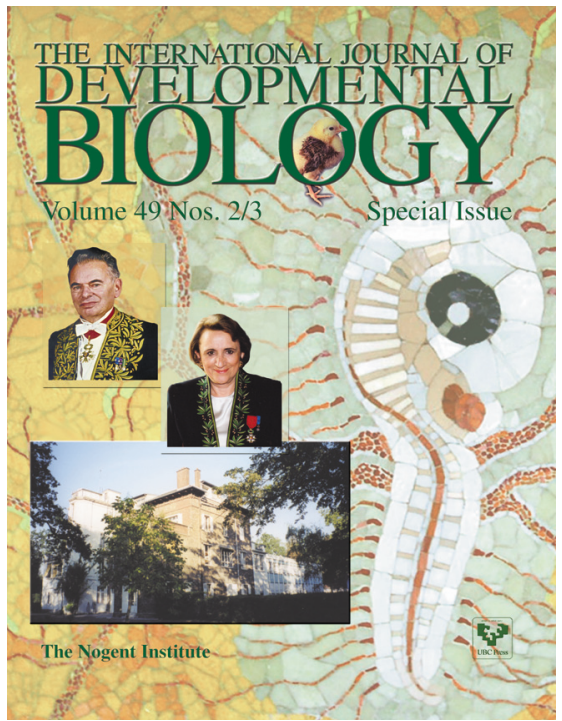

